\title{
Clinico - Pathological Correlation of Thyroid Swellings
}

\author{
Jain $\mathbf{S}^{1}$, Nayak $\mathbf{R}^{2}$, Totade $\mathrm{S}^{3}$, Shukla $\mathbf{N}^{4}$ \\ ${ }^{1}$ Dr. Sharad Jain, Associate professor, ${ }^{2}$ Dr. Rashmi Nayak, Assistant professor, ${ }^{3}$ Dr.Sanjay Totade, Professor and head, \\ ${ }^{4}$ Dr Neelam Shukla. All are affiliated with department of Pathology, NSCB Medical College, Jabalpur, MP, India
}

Address for Correspondence: Dr Rashmi Nayak, E mail: vijaynayak123@gmail.com

\begin{abstract}
Introduction: Thyroid being an actively functioning gland is subjected to series of disturbances, both physiological and pathological. It may be affected by various disorders like developmental, inflammation, hyperplastic and neoplastic that may present with similar sign and symptoms. Almost any disorder of thyroid can present as a nodule. The thyroid nodule is common problem faced by the clinicians as they cause apprehension due to their unpredictable behaviour. Method: A total of 110 patients were studied. All patients underwent FNAC after prior consent. FNAC was done with aseptic precautions by using 23 gauze needles, non-aspiration technique. Material obtained was smeared on 2 glass slides, air dried and stained with Leishmann's stain. Remaining wet slides fixed by using ethanol and were stained with hematoxylin and eosin (H\&E) method. Pre-operative FNAC results were then compared with the definitive histological diagnosis. Result: Incidence of malignancy in thyroid nodules was $8.18 \%$. Sensitivity and specificity in the present study was $85.7 \%$ and 96.4\%, respectively with PPV, NPV and diagnostic accuracy of 92.3\%, 93.1\% and 92.9\%, respectively. False positive and false negative error rate was 2.4 and 4.8 respectively. Conclusion: Definitive diagnosis of either benign or malignant can be suggested by FNAC and accordingly line of management can be planned. So we can avoid unnecessary surgeries for benign lesions and reduce the cost of hospitalisation.
\end{abstract}

Key words: Fine Needle Aspiration Cytology, Thyroid Function Tests, Follicular Neoplasm of thyroid

\section{Introduction}

Thyroid being an actively functioning gland is subjected to series of disturbances, both physiological and pathological. It may be affected by various disorders like developmental, inflammation, hyperplastic and neoplastic that may present with similar sign and symptoms. Almost any disorder of thyroid can present as a nodule. The thyroid nodule is common problem faced by the clinicians as they cause apprehension due to their unpredictable behaviour.

Prevalence of palpable thyroid nodule in non-iodine deficient area is about $4-7 \%$ in general adult population and 0.2 to $1.5 \%$ in children $[1,2]$. Now a days due common use of USG in clinical practice the incidence of thyroid nodule has rises to $14-50 \%[2,3,4]$. Benign lesions are more common in thyroid and less than $5 \%$ are actually malignant $[2,4]$.

In India the scenario is quite different. India has world's biggest "goitre Belt" in the subhimalayan region and the

Manuscript received: $10^{\text {st }}$ Oct 2014

Reviewed: $19^{\text {th }}$ Oct 2014

Author Corrected: $10^{\text {th }}$ Nov 2014

Accepted for Publication: $13^{\text {th }}$ Nov 2014 average prevalence of goiter is around 40\%. Though goiter is quite common, cancer of thyroid is comparatively rare constituting less than $1 \%$ of cancer $[5]$.

Both benign and malignant lesions of thyroid commonly present with a nodule. Since most of the thyroid nodules are benign it is essential to identify patients who are likely to be benefited from surgery and thus avoid essential diagnostic surgery in all cases. This has been attempted on the basis of several diagnostic tools like clinical examination, TSH level, ultrasound, Thyroid scan and FNAC. Among the diagnostic tools currently available fine needle aspiration is considered as the most reliable tool and is often used as the first screening test for the diagnosis of thyroid nodule. Fine needle aspiration cytology is the study of cells obtained by fine needle under vaccum. Some cells with little tissue fluid are sufficient to make a morphological diagnosis. It has emerged as the most accepted, accurate diagnostic procedure which is easy, quick, cost effective and cosmetically sound $[1,6,7,8]$. But there are some limitations of FNAC; the most important is the 
indeterminate or suspicious results i.e. inability to distinguish between follicular adenoma and carcinoma, other includes inadequate or nondiagnostic smear, sampling error due to large nodule or very small ones and inexperience of the cytopathologist $[4,9]$. Some of these problem can be solved by USG guided FNAC which helps in taking sample from more representative area.

Benign nodules can be caused by adenomas, colloid nodules, cysts, infectious nodules, lymphocytic or granulomatous thyroiditis, hyperplastic nodules, and congenital anomalies. Malignant nodules are classified as: Differentiated: a) papillary adeno-carcinoma, and b) follicular adeno-carcinoma, medullary carcinoma, undifferentiated - a) small cell, b) giant cell, and c) carcinosarcoma, and miscellaneous - a) lymphoma/sarcoma, b) squamous cell carcinoma, c) fibrosarcoma, d) mucoepithelial carcinoma, and e) metastatic tumors.

The present study was conducted in Netaji Subhash Chandra Bose Medical College and Hospital, Jabalpur (M.P) during September 2012 to October 2013 with the aims of evaluating accuracy of FNAC in the diagnosis of nodular lesions of thyroid in comparison to other diagnostic modalities, and to make early and accurate differentiation of benign and malignant thyroid nodules so that unnecessary surgery in benign cases can be avoided.

\section{Materials and Methods}

The present study was a prospective study carried out in the Department of Pathology, N.S.C.B Medical College Jabalpur, M.P (India), on both indoor and outdoor patient requiring FNAC of the thyroid lesions between September 2012 to September 2013

A total of 110 patients were studied. Inclusion criteria included all patients with thyroid enlargement irrespective of age and sex. In all patients detail clinical findings, USG, and TFT were recorded. All patients underwent FNAC after prior consent.

Technique of FNAC: FNAC was done with aseptic precautions by using 23 gauze needles, non-aspiration technique. Material obtained was smeared on 2 glass slides, air dried and stained with Leishmann's stain. Remaining wet slides fixed by using ethanol and were stained with hematoxylin and eosin (H\&E) method. Adequate aspirates were taken, when cytology smears contain five to six groups of well-preserved follicular cells, with each group containing 10 or more cells [10].

However, adequacy also depends upon the lesion being aspirated. For example, in case of colloid goitre, FNAC may yield only colloid with scanty cells, but it is adequate, if the lesion is taken into consideration. No serious complications occurred in our study. Only the pain for few minutes after aspirations was noted in few cases. Out of 110 cases 42 patients underwent thyroid surgery. FNAC smears results were divided into four categories-Benign (Negative), Suspicious (Intermediate), Malignant (Positive) and Non-diagnostic (Unsatisfactory).

Patients with benign cytodiagnosis did not have malignancy. The epithelial elements showed uniformity of cell size, shape and nuclear structure. Colloid was present in large amount and cellularity was low. Benign nodules included multi-nodular goitre, hyperplastic goitre, colloid goitre, Grave's disease, Hashimoto's thyroiditis, Dequervain thyroiditis and colloid cysts. Suspicious (Intermediate) cytodiagnosis was made when smear was hypercellular and a pattern suggestive of follicular or hurthle cell neoplasm or atypical features suggestive of but not diagnostic for malignancy was present. Malignant smear had cytological finding indicating the presence of malignant cells consistent with primary or metastatic thyroid cancer. Malignant nodules included papillary carcinoma, medullary carcinoma, poorly differentiated carcinoma, anaplastic carcinoma, and lymphoma.

Non-diagnostic (Unsatisfactory) specimens were found to be inadequate for proper cytopathologic interpretation due to presence of cystic fluid or haemorrhagic material and very few cells or excessive drying. Pre-operative FNAC results were then compared with the definitive histological diagnosis. The sensitivity, specificity, diagnostic accuracy, positive predictive valve (PPV) and negative predictive value (NPV), false positive and false negative error rate of FNAC in diagnosing thyroid malignancy was calculated.

\section{Results}

During the study period 110 fine needle aspirations were carried out for thyroid lesion. Out of which 42 cases were subjected to histopathological study. Age group of these 110 patients ranged between 10-75 yrs with the mean age of 38+/- 13.9yrs. Majority of patients were in the age group of 31-40yrs, predominantly patients were females accounting for 92(83.6\%) of total 110 cases with male to female ratio of $1: 5.1$. 
Table 1: Age \& sex distribution of the cases

\begin{tabular}{|c|c|c|c|}
\hline Age group & Male & Female & Total \\
\hline $10-20$ & 3 & 7 & 29 \\
\hline $21-30$ & 2 & 29 & 35 \\
\hline $31-40$ & 6 & 13 & 14 \\
\hline $41-50$ & 1 & 11 & 6 \\
\hline $51-60$ & 4 & 4 & 1 \\
\hline $61-70$ & 2 & 1 & $\mathbf{1 1 0}$ \\
\hline $71-80$ & 0 & $\mathbf{9 2}$ & 27 \\
\hline Total & $\mathbf{1 8}$ & & \\
\hline
\end{tabular}

All cases (110) presented with midline swelling in front of neck, 24(21.8\%) had associated dysphagia and 20(18.2\%) had hoarseness of voice. Duration was less than a year in most of the patients 74 (67.2\%). In present study 100 (91\%) case were in clinical euthyroid state, $6(5.4 \%)$ had hyperthyroidism and 4(3.6\%) were in a hypothyroid state. FNAC yielded adequate cell samples in $108(98.1 \%)$ cases and inadequate in $2(1.9 \%)$.

On cytological study out of 110 cases with thyroid lesions, 95(86.3\%) were classified as benign; 2(1.8\%) as malignant; $11(10 \%)$ as suspicious and $2(1.8 \%)$ aspirates as inadequate. Among the 95 non-neoplastic lesions, colloid goiter was the commonest 84(76.4\%) followed by Dequervain's Thyroiditis 2(1.8\%), Lymphocytic Thyroiditis 2(1.8\%) and Nodular Goiter were also 2(1.8\%). Other less common lesions were Adenomatous Goitre, Hyperactive colloid Goitre and colloid cyst. Among the malignant lesions $(\mathrm{n}=2)$ all were papillary carcinoma $2(1.8 \%)$ and all the suspicious lesions $11(10.0 \%)$ were follicular neoplasm on cytology.

Table 2: Shows correlation of clinical and FNAC diagnosis.

\begin{tabular}{|c|c|c|c|c|c|c|c|c|c|}
\hline \multicolumn{10}{|c|}{ FNAC Diagnosis } \\
\hline $\begin{array}{c}\text { Clinical } \\
\text { diagnosis }\end{array}$ & $\begin{array}{c}\text { Colloid } \\
\text { goitre }\end{array}$ & $\begin{array}{c}\text { Adenomatous } \\
\text { goitre }\end{array}$ & $\begin{array}{c}\text { Nodular } \\
\text { goitre }\end{array}$ & Thyroiditis & cyst & $\begin{array}{l}\text { Graves } \\
\text { disease }\end{array}$ & FN & $\begin{array}{l}\text { Papillary } \\
\text { carcinoma }\end{array}$ & $\mathbf{U S}$ \\
\hline $\begin{array}{c}\text { Colloid } \\
\text { goitre(92) }\end{array}$ & 80 & 1 & 2 & & & & 7 & & 2 \\
\hline Thyroiditis(5) & 1 & - & - & 4 & - & - & - & - & - \\
\hline $\begin{array}{c}\text { Graves } \\
\text { disease (2) }\end{array}$ & - & - & - & - & - & 1 & 1 & - & - \\
\hline $\begin{array}{c}\text { Solitary } \\
\text { nodule(5) }\end{array}$ & - & - & - & - & 3 & - & 2 & - & - \\
\hline Malignancy(6) & 3 & - & - & - & - & - & 1 & 2 & - \\
\hline Total(110) & 84 & 1 & 2 & 4 & 3 & 1 & 11 & 2 & 2 \\
\hline
\end{tabular}

Table 2 show correlation between clinical and FNAC diagnosis. Clinico-cytological correlation is highest in case colloid goitre (87\%), in case of thyroiditis $80 \%$ and least in malignancy $(33 \%)$.

Table 3-FNAC and Histological correlation

\begin{tabular}{|l|c|c|c|c|}
\hline \multicolumn{2}{|c|}{ FNAC diagnosis } & Histopathological Diagnosis & $\begin{array}{c}\text { Follicular } \\
\text { carcinoma }\end{array}$ & $\begin{array}{c}\text { Papillary } \\
\text { carcinoma }\end{array}$ \\
\hline $\begin{array}{l}\text { Colloid } \\
\text { goitre(29) }\end{array}$ & 27 & 2 & - & - \\
\hline Follicular neoplasm(11) & 1 & 3 & 7 & - \\
\hline Papillary carcinoma(2) & - & - & - & 2 \\
\hline Total(42) & 28 & 5 & 7 & 2 \\
\hline
\end{tabular}


Table 3 shows correlation between FNAC and Histology. Among 95 non-neoplastic lesions diagnosed by cytology, histopathological study was done in 29 cases of these 29 cases diagnosed cytologically as colloid goitre, histological examination confirmed the diagnosis of colloid goitre in 27 cases. Two cases which were diagnosed as colloid goitre on FNAC turned out to be follicular adenoma on histology. Cyto-histological concordance rate in colloid goitre was $93.1 \%$.

Out of 110 cases 42 were operated. Histopathological diagnosis in these 42 operated cases showed malignancy in $09(21.4 \%)$ and benign lesions in 33(78.6\%). Most common benign lesion on histopathological report was colloid goitre (66.7\%) and the most common malignancy was follicular carcinoma (16.7\%) while papillary carcinoma constitutes only $4.7 \%$.

Cytological diagnosis of papillary carcinoma was made in 2 cases. Histopathological study carried out in both cases and it was concurrent in both cases. Thus the concordance rate in case of papillary carcinoma was $100 \%$. Of the 11 suspicious cases, histopathological studies were possible in all 11 cases. Among these, 7(63.6\%) were follicular carcinoma, 3(27.3\%) follicular adenoma and 1(9.1\%) adenomatous goitre. Cytohistologic correlation in this group were not considered due to it's cytologically indeterminate-nature. The incidence of suspicious cases in the present study was $10 \%$. And the incidence of malignancy in suspicious cases was $63.6 \%$. Overall, cytohistological correlation in all categories excluding the suspicious group was $93.5 \%$.

Table 4: Presence of metastasis in cases of thyroid carcinoma

\begin{tabular}{|c|c|c|c|}
\hline & Metastasis Present & Absent & Total \\
\hline Follicular carcinoma & $4(57 \%)$ & $3(43 \%)$ & 7 \\
\hline Papillary carcinoma & 0 & 2 & 2 \\
\hline
\end{tabular}

Table 4 show out of 7 cases of follicular carcinoma, 4 cases had metastasis at the time of diagnosis. Out of 4,1 showed lung metastasis, 1 vertebral metastasis, 1 orbital metastasis, 1 orbital and cutaneous metastasis. Patients of orbital metastasis presented with progressive enlarging mass and proptosis with duration $<6$ months. Both were involving left orbit. Patient of cutaneous metastasis presented with slowly enlarging erythematous mass in right side of face since one year. Orbital and cutaneous metastasis was confirmed by cytology and vertebral by the histopathology.

Sensitivity and specificity in our study was $85.7 \%$ and $96.4 \%$, respectively. Positive predictive value which measures true positive, was $92.3 \%$ in present study and Negative predictive value which measures true negative was $93.1 \%$ in present study. Both false positive and false negative rate was $<5 \%$ giving high diagnostic accuracy of $92.9 \%$. It shows FNAC is simple, safe screening as well as diagnostic test in evaluating thyroid swelling with some limitations. The major limitation of thyroid cytology is that it cannot differentiate between follicular adenoma and carcinoma.

\section{Discussion}

Fine needle aspiration is the initial modality in the investigation of thyroid lesions. It is most accepted, accurate diagnostic procedure which is easy, quick, cost effective and cosmetically sound. It reduces the incidence of unnecessary surgery.

Ages of the patients ranged between 10-75 years. In present study as well as in various other studies, it was most common in the $3^{\text {rd }}$ and $4^{\text {th }}$ decades $[11,12,13,14]$.

Median age was $38+\ldots 13.9$ yrs in the present study which was comparable to A. Martinek [12]. In the present study 92 were female and only 18 were males with male to female ratio (M:F) of 1:5.1. Sex distribution was comparable to study by E.A Sinna et al whose study showed M:F ratio of 1:5.2, and Screaton NJ et al also showed $\mathrm{M}: \mathrm{F}=1: 5 \cdot 2 \cdot[8,15]$. It has been well documented in various studies that all types of thyroid lesions occur more commonly in the females $[11,13,16]$.

In the present study $100(91 \%)$ cases were in clinical euthyroid state, 6(5.4\%) had hyperthyroidism and $4(3.6 \%)$ were in a hypothyroid state. Out of 6 hyperthyroid cases, 3 cases were of colloid goitre, one case was of Grave's disease, one case was of Follicular neoplasia and one case was of Hashimoto's thyroiditis on FNAC. Out of 4 hypothyroid cases, all were diagnosed as colloid goitre on FNAC. Other authors had also reported most patients of thyroid nodule as euthyroid [18,19,20].

These findings suggest that TFT is just a preliminary tool in evaluation of nodular lesions of thyroid and lacks sensitivity and specificity in the diagnosis of thyroid nodule.

Available online at: www.ijmrr.in 556 | P a g e 
In the present study FNAC results were broadly categorised into four groups- benign, malignant, suspicious and unsatisfactory. Out of 110 cases 95(86.3\%) were benign; 2(1.8\%) malignant; $11(10 \%)$ suspicious and $2(1.8 \%)$ were inadequate. The reported rate of benign cytological results ranged from 51 to $90 \%$, rate of malignant cytological findings ranged from $1 \%$ to $16 \%$, rate of suspicious results ranged from $4 \%$ to $23 \%$ and the rate of nondiagnostic results varied from $1.6 \%$ to $31 \%[5,6,9,21,22,23,24]$. Our results also fall within the reported range.

In the present study incidence of adequate sample was $98.1 \%$ and the incidence of inadequate samples was $1.8 \%$. Number of factor are important in affecting the adequacy of thyroid aspirate sample. Mandrekar et al 1995 observed that selection of cases with prior investigations such as thyroid scan and ultrasonography will yield a lower number of inadequate samples as compare to FNAC as initial modaliyt [21].

Burch et al reported a high insufficiency rate of $31 \%$, which they attributed to relative inexperience of many of the aspirators. Another contributor to the higher insufficiency rate was inconsistent reporting of cytology results by a large number of staff pathologists [22]. Raabs et al gave the reason for inadequate FNAC was different criteria of adequacy used by cytologist and because of poor sampling by the radiologist and clinician [25].

In various studies 0.5 to $9.3 \%$ of benign cytological finding turn out to be malignant histopathologically $[6,17,21,24,26,27]$. In the present study false negative rate was $4.8 \%$ which is comparable to recent studies.

This may be due to insufficient sampling, sampling from non-representative area and cytological misdiagnosis. False positive rate was $2.4 \%$. FP diagnosis is mainly due to misinterpretation of cellular atypia.

10 to $56 \%$ of suspicious cytological finding proved to be malignant on histopathological examination $[6.17,21,24,26,27,28]$. In the present study $63.6 \%$ of the suspicious cases were malignant following surgical procedure.

Thyroid lesions classified as malignant on FNAC have a high risk of being malignant on surgical follow up was observed in previous studies as well as in the present study. $\quad[6,17,21,24,26,28]$. Cyto-histopathological correlation was established in $86 \%$ to $100 \%$ cases. Results of the present study also fall within the reported range.

\begin{tabular}{|c|c|c|c|c|c|c|}
\hline Series & Year & Sensitivity & Specificity & PPV & NPV & DA \\
\hline Agrawal S[5] & 1995 & 76.5 & 95.9 & 86.7 & 92.2 & 90.9 \\
\hline Holleman et al [29] & 1995 & 84 & 52 & 53 & 83 & 65 \\
\hline Burch et al [22] & 1996 & 80 & 73.2 & 55.8 & 90 & 75.2 \\
\hline Lopez et al [30] & 1997 & 90 & 99.8 & 98 & 99 & 99 \\
\hline Leonard\& Melcher [27] & 1997 & 88 & 78 & 46 & 97 & 80 \\
\hline Baloch et al [6] & 1998 & 92 & 84 & 73.3 & 98.7 & \\
\hline Cap et al [31] & 1999 & 86 & 74 & 34 & 97 & 75 \\
\hline Settakorn J et al [32] & 2001 & 90.4 & 85.7 & 83.3 & 93.7 & 92.5 \\
\hline Morgan et al [17] & 2003 & 55 & 73 & 70 & 67.4 & 67.2 \\
\hline Mahar et all [33] & 2006 & 98 & 70 & 91 & 93 & 91 \\
\hline Haberal [34] & 2009 & 92.6 & 91.6 & 83.5 & 96.5 & 91.9 \\
\hline Moosa et al [35] & 2010 & 77.7 & 98.9 & 87.5 & 97.8 & \\
\hline Gupta $\mathrm{M}$ et al [11] & 2010 & 80 & 86.6 & 80 & 86.6 & 13.3 \\
\hline Wahid F et al [14] & 2011 & 88.1 & 77.5 & 80.4 & 86.1 & 82.9 \\
\hline Pandey et al [26] & 2012 & 57.1 & 90 & 70.6 & 83.3 & 90.3 \\
\hline EA sinna [8] & 2012 & 92.8 & 94.2 & 94.9 & 91.8 & 93.6 \\
\hline Muratli et al [24] & 2014 & 87.1 & 64.6 & 76.1 & 79.5 & 77.3 \\
\hline Present study & 2014 & 85.7 & 96.4 & 92.3 & 93.1 & 92.9 \\
\hline
\end{tabular}


Table 5 is a review of recent series on various statistical indices like sensitivity, specificity, positive predictive value, negative predictive value and diagnostic accuracy of FNAC of thyroid.

The sensitivity rate in above series ranged from $76 \%$ to $98 \%$ with the exception of $55 \%$ in the study by Morgan et al (2003), in Australia [17].

Our results were comparable to the series with a sensitivity of $85.7 \%$. The specificity rates varied from $73 \%$ to $98.9 \%$ with the exception of Holleman et al (1995), who reported the specificity rate as low as $52 \%$ [29].

Our results were comparable to the series with specificity rate of $96.7 \%$. Analysis of the above series reveals an overall positive predictive value (PPV) ranging from $34 \%$ to $98 \%$ which implies presence of malignancy.

A negative predictive value (NPV) i.e. negative for malignancy in the above series ranged from $67.4 \%$ to $98.7 \%$.

Our results are comparable with a PPV of $92.3 \%$ and a NPV of $93.1 \%$. This confirms FNAC as a good screening procedure for thyroid lesions.

The diagnostic accuracy of FNAC ranged from $65 \%$ to $99 \%$ depending upon the expertise of the aspirator and cyto-pathologist interpreting the sample $[5,6,8,11,14,17,22,24,27,29-35]$.

The diagnostic accuracy in present study was $92.9 \%$.

These data suggest that that fine needle aspiration cytology is slightly more specific than sensitive in detecting thyroid cancer and confirm it as a reliable diagnostic test.

\section{Conclusions}

FNAC of thyroid lesions is safe, simple, cost effective accurate method for management of palpable thyroid lesions.

Non aspiration technique is superior to other technique; it yields good cellularity and decreases the obscuring effect of blood. No major complication was faced in any case.

The procedure was well tolerated by all the patients and could easily be repeated.

There was a good cytohistopathological correlation with sensitivity of $85.7 \%$ and specificity of $96.4 \%$. Thus in more than two third patients a definitive diagnosis of either benign or malignant can be suggested by FNAC and accordingly line of management can be planned. So we can avoid unnecessary surgeries for benign lesions and reduce the cost of hospitalisation.

\section{Funding: Nil \\ Conflict of interest: Nil \\ Permission from IRB: Yes}

\section{References}

1. Gharib H. Fine-needle aspiration biopsy of thyroid nodules: advantages, limitations, and effect. Mayo Clin Proc. 1994;69(1):44-49.

2. Ezzat S, Sarti DA, Cain DR, Braunstein GD. Thyroid incidentalomas prevalence by palpation and ultrasonography. Arch Intern Med. 1994;154(16):18381840 .

3. Yeung MJ, Serpell JW. Management of the solitary thyroid nodule. Oncologist 2008;13(2):105-12.

4. Cappelli C, Castellano M, Pirola I, Gandossi E, De Martino E, Cumetti D, et al. Thyroid nodule shape suggests malignancy. Eur J Endocrinol. 2006 Jul;155(1): 27-31.

5. Agrawal S. Diagnostic accuracy and role of fine needle aspiration cytology in management of thyroid nodules. Journal of Surgical Oncology. 1995;58(3):168172.

6. Baloch MN, Ali S, Ansari MA, Maher M. contribution of fine needle aspiration cytology (FNAC) in the diagnosis of malignant thyroid nodules. Pak J Surg.Mar 2008; 24(1):19-21.

7. Bagga P K, Mahajan N C. Fine needle aspiration cytology of thyroid swellings: How useful and accurate is it?. Indian J Cancer 2010 Oct-Dec;47(4):437-42.

8. E.A. Sinna, N. Ezzat, Diagnostic accuracy of fine needle aspiration cytology in thyroid lesions, Journal of the Egyptian National Cancer Institute: 2012 June;24 (2): 63-70.

9. Uma Handa, Sukant Garg, Harshmohan, Nitin Nagarkar: Role of fine needle aspiration cytology in diagnosis and management of thyroid lesions, a study on 434 patients. Journal of Cytololgy: 2008; 25(1) :13-17. 
10. Gharib H, Goellner JR. Fine-needle aspiration biopsy of thyroid: an appraisal. Ann Intern Med 1993 Feb $15 ; 118(4): 282-9$. .

11. Gupta M, Gupta S, Gupta VB. Correlation of fine needle aspiration cytology with histopathology in the diagnosis of solitary thyroid nodule. $J$ Thyroid Res. 2010;18:37-40.

12. A. Martinek, J. Dvorackovia, M. Honka, et al. Importance of Guided Fine needle aspiration Cytology (FNAC) for the diagnosis of Thyroid Nodules-Own Experience. Biomed Papers. 2004; 148(1),45-50

13. Quddus MA, M Alimuzzaman, \& MKH Sardar. "Role of FNAC in the Evaluation of Solitary Cold Thyroid Nodule." Journal of Shaheed Suhrawardy Medical College [Online], 2012;4(1): 15-17. Web. 25 Oct. 2014,

14. Wahid FI, Khan SF, Rehman HU, Khan IA. Role of fine needle aspiration cytology in diagnosis of solitary thyroid nodules. Iranian Journal of Otorhinolaryngology. 2011;23(4):111-118.

15. Screaton NJ, Berman LH, Grant JW. US-guided core-needle biopsy of the thyroid gland.Radiology. 2003 Mar;226(3):827-32. .

16. Alam M, Qureshi H, Jan QA. Accuracy of FNAC as a diagnostic modality in the management of solitary thyroid nodule. J Med Sci. 2010;18:94-61

17. Morgan JL, Serpell JW, Cheng MSP. Fine-needle aspiration cytology of thyroid nodules: how useful is it? ANZ Journal of Surgery. 2003;73(7):480-483.

18. Sengupta A, Pal R, Kar S, Zaman FA, Sengupta S, Pal S. Fine needle aspiration cytology as the primary diagnostic tool in thyroid enlargement. Journal of Natural Science, Biology and Medicine. 2011;2(1):113118.

19. V RC, B V, M KK, Durbesula PT, Rao PS. A study on the clinical manifestations and the incidence of benign and malignant tumors in a solitary thyroid nodule. Int J Res Med Sci. (2013), [cited October 25, 2014]; 1(4): 429-434.

20. Russel CFJ. The management of the solitary thyroid nodule. In: Johnson CD, Taylor I, editors. Recent advances in surgery. Vol. 17. London: ChurchillLivingstone; 1994. pp. 4-16.
21.Mandreker SR, Nadkarni NS, Pinto RG, Menezes S. Role of FNAC as the initial modality in the investigation of thyroid lesions. Acta Cytol 1995 Sep-Oct;39(5):898904.

22. Burch HB, Burman KD, Reed HL, Buckner L, Raber T, Ownbey JL: Fine needle aspiration of thyroid nodules. Determinants of insufficiency rate and malignancy yield at thyroidectomy. Acta Cytol 1996, 40 (6):1176-1183.

23. Kumar H, Daykin J, Holder R, et al. Gender, clinical findings, and serum thyrotropin measurements in the prediction of thyroid neoplasia in 1005 patients presenting with thyroid enlargement and investigated by fine-needle aspiration cytology. Thyroid.1999 Nov;9 (11): 1105-9.

24. Muratli A, Erdogan N, Sevim S, Unal I, Akyuz S. Diagnostic efficacy and importance of fine-needle aspiration cytology of thyroid nodules. J Cytol 2014 Apr;31(2):73-8.

25. Raab SS, Vrbin CM, Grzybicki DM, Sudilovsky D, Balassanian R, Zarbo RJ, et al. Errors in thyroid gland fine-needle aspiration. Am J Clin Pathol 2006 Jun;125(6):873-82.

26. Pandey P, Dixit A, Mahajan NC. Fine-needle aspiration of the thyroid: A cytohistologic correlation with critical evaluation of discordant cases. Thyroid Res Pract. 2012;9(2):32-9.

27. Leonard N, Melcher DH. To operate or not to operate? The value of fine needle aspiration cytology in the assessment of thyroid swellings. J Clin Pathol. 1997 Nov;50(11):941-3.

28. Wang CC, Friedman L, Kennedy GC, Wang H, Kebebew E, Steward DL, et al. A large multicenter correlation study of thyroid nodule cytopathology and histopathology. Thyroid. 2011 Mar;21(3):243-51.

29. Holleman F, Hoekstra JB, Ruitenberg HM. Evaluation of fine needle aspiration (FNA) cytology in the diagnosis of thyroid nodules. Cytopathology 1995 Jun;6(3):168-75.

30. Lopez LH, Canto JA, Herrera MF, GamboaDominguez A, Rivera R, Gonzalez O, et al. Efficacy of fine-needle aspiration biopsy of thyroid nodules: Experience of a Mexican institution. World J Surg. 1997 May;21(4):408-11. 
31. Cáp J, RyŠka A, Rehorková P, Hovorková E, Kerekes Z, Pohnetalová D. Sensitivity and specificity of the needle aspiration biopsy of the thyroid: clinical point of view. Clin Endocrinol (Oxf) 1999 Oct;51(4):509-15.

32. Settakorn J, Chaiwun B, Thamprasert K, Wisedmongkol W, Rangdaeng S. Fine needle aspiration of the thyroid gland. J Med Assoc Thai. 2001 Oct;84(10):1401-6.

33. Mahar SA, Husain A, Islam N. Fine needle aspiration cytology of thyroid nodule: Diagnostic accuracy and pitfalls. J Ayub Med Coll Abbottabad. 2006 OctDec;18(4):26-9.
34. Haberal AN, Toru S, Ozen O, Arat Z, Bilezikçi B. Diagnostic pitfalls in the evaluation of fine needle aspiration cytology of the thyroid: Correlation with histopathology in 260 cases.Cytopathology. 2009 Apr;20(2):103-8.

35. Moosa FA, Khan FW, Sultan N, Rao MH. Up to what extent FNAC is accurate in detecting malignancy in solitary thyroid nodule? A comparison with postoperative histopathology findings. Med Chann. 2010; 16:280-3.

\section{How to cite this article?}

Jain S, Nayak R, Totade S, Shukla N. Clinico - Pathological Correlation of Thyroid Swellings. Int J Med Res Rev 2014;2(6):553- 560. doi:10.17511/ijmrr.2014.i06.08 